\title{
INDIVIDUAL ASSETS, MARKET STRUCTURE AND THE DRIVERS OF RETURN
}

\author{
Steven Devaney \\ Investment Property Databank Ltd \\ 7-8 Greenland Place, London NW1 0AP UK \\ steven.devaney@ipdindex.co.uk \\ Colin Lizieri \\ University of Reading Business School \\ Department of Real Estate \& Planning, \\ Whiteknights, Reading RG6 6AW UK \\ c.m.lizieri@reading.ac.uk Contact Author
}

Paper Presented to the European Real Estate Society Conference

Dublin, June 2005 


\title{
Individual Assets, Market Structure And The Drivers Of Return ${ }^{1}$
}

\author{
Steven Devaney $\quad$ Investment Property Databank Ltd. ${ }^{2}$ \\ Colin Lizieri $\quad$ University of Reading Business School ${ }^{3}$ \\ Key Words: $\quad$ Portfolio Structure, Real Estate; Return Generation Process
}

\section{Introduction}

Investors placing significant amounts of capital in direct ownership of real estate confront a problem that relates to the characteristics of the asset class. Due to the large lot size, the indivisibility of individual assets and heterogeneity, it is difficult to structure a portfolio that diversifies away specific risk or that tracks the performance of the underlying market. This difficulty is compounded by the absence of a central public market place (making the acquisition search process and the matching of buyers and sellers more complex) and by the need for management inputs that involve direct interaction with the asset and its tenants.

Pragmatically, investors have sought to reduce these management and investment strategy issues by subdividing the asset class into groupings. It is implicitly assumed that the behaviour of returns within these groupings will be more homogenous than across groupings. Typically the grouping is carried out in terms of property type (sector) and geography (region). Thus, "within property" portfolio allocation decisions are made on a sector-region basis and internal or external investment surveying and asset management teams are similarly organised. The sector-region structure is reinforced by reporting (for example in property companies' annual reports) and by performance benchmarking. Within the UK, the Investment Property Databank's performance attribution service uses a set of geography and property type segments to break down fund performance into fund structure and stock selection components.

Such analyses, while driven by practical considerations, are valuable only insofar as return performance reflects the sector-region structure: that is, if returns of buildings in each sector-region grouping exhibit similar behaviour. A priori, one might expect differences across sectors if the drivers of demand differ (for example, if the demand for business services, consumer expenditure and industrial output are driven by separate cycles); similarly there may be regional (or, more likely, local) economic factors - the decline of a dominant industry or the closure of a major employer will have a geographical impact that cuts across sectors. However, it is an empirical question as to whether the variation in returns is substantially captured by property type and geography or whether there are other factors contributing to the return generating process.

\footnotetext{
${ }^{1}$ The views of the authors do not necessarily represent the views of their organisations. All individual property data was processed at IPD to protect investor confidentiality.

${ }^{2}$ steven.devaney@ipdindex.co.uk Investment Property Databank Ltd 7-8 Greenland Place, London NW1 0AP UK

${ }^{3}$ c.m.lizieri@reading.ac.uk Department of Real Estate \& Planning, University of Reading Business School, Whiteknights, Reading RG6 6AW UK: Contact Author
} 
Prior UK research (reviewed below) has tended to confirm a strong sectoral dimension to return patterns (typically with retail distinct from office and industrial property). Results relating to geography are more mixed. There does seem to be a regional dimension, but one based on economic function rather than the conventionally used administrative regions. Research at town level has been inconclusive. In the United States, as might be expected given geographical scale, there seem to be a clearer regional dimensions. Once again, economic regions outperform pure administrative or statistical regions.

However, the majority of the UK research - with Cullen (1993) an exception does not deal with individual property returns. Researchers either rely upon aggregate data (e.g. "all retail property in Scotland") or on hypothetical data (estimated best returns and yields in a town). This does not conform to the stock selection problem facing the individual investor, who must acquire actual properties within those property types and geographic entities. The research findings hold if - and only if - the returns of a particular building in a particular location behave in a similar fashion to similar buildings of that same type in that same location. That is the problem addressed in this paper.

We analyse individual property returns from some 1,200 UK properties from a sub-set of the Investment Property Databank. Examining these individual return series, we ask whether the conventional sector-region boundaries capture variations in return, and if there are other characteristics of properties that help explain the return generation process (and, hence, would improve both asset allocation and performance benchmarking processes). After reviewing the existing literature on diversification in UK commercial real estate portfolios, we introduce our data. The fourth section reviews the results from use of exploratory data analysis techniques (discriminate analysis, cluster analysis, factor analysis) and attempt to characterise the return generating process. Finally, our concluding section points to practical implications of the findings.

\section{Prior Research}

In both UK and US markets, there exists a considerable body of literature examining the structure of real estate portfolios and the impact of structure on diversification and performance. Reviews of the US literature can be found in Viezer (2000) and Nelson \& Nelson (2003). While there are major concerns over the applicability of the mean-variance, portfolio optimisation techniques used in the majority of the research papers to direct real estate portfolios, the issues discussed have a direct practical implication for investment. Worzala et al. (2002) found that portfolio diversification by geography and property type was the fourth ranked priority for research amongst US investors surveyed. The literature reviewed here focuses on UK research.

The majority of papers on the topic in the UK use either appraisal-based aggregated returns data from Investment Property Databank or hypothetical returns data based on market appraisals by CB Richard Ellis (in their earlier guise as CBHP and Hiller Parker). In the former case, data are available by sector, at a regional level and for individual towns. 
However aggregated, though, individual building-level returns are suppressed and there must be a minimum number of properties in a market before data are released. For the hypothetical Hillier Parker data, rents and capitalisation rates are estimated for town-level markets. From this, one can construct a shadow return (although actual returns would vary according to lease cycle and there are no periodic cost adjustments). In both cases, there is no mechanism for judging how representative cited returns are for individual buildings in each market, nor how varied are the distribution of returns within markets.

In a series of papers, Byrne and Lee (1988, 2000, 2001, 2003; Lee, 2003) have explored the structure of UK directly-held real estate portfolios. Some strong common findings emerge - notably the predominance of diversification by sector over diversification by geography and the cohesion of the retail sector. They also note that the risk faced by an individual investor holding a portfolio is distinct from the "average" portfolios resulting from aggregate analysis. In Byrne \& Lee (2000), local market data from IPD is used to estimate a correlation between markets and a resultant risk-reduction index based on Schuck \& Brown (1997). These correlations are then used in a sector-region framework with a Monte Carlo simulation process to generate hypothetical portfolios which prove to be higher risk and with different diversification structures than the aggregate model might suggest. This problem is compounded when the assumptions of equal weighting are relaxed confirming Morrell's (1993) UK findings. Byrne \& Lee (2003) re-examine the portfolio size issue by examining fund level data in a single index framework. They find, contrary to theory, a positive relationship between portfolio size and systematic risk suggesting compositional differences between large and small portfolios.

Hoesli et al. (1997) and Hamelink et al. (2000) utilise cluster analysis using Hillier Parker local market data for 156 property type-town "sub-markets" Hoesli et al. (1997) find that sector dominates geography, retail being distinct from office and industrial property. Geography is important - but spatial groupings that emerge do not conform to conventional administrative boundaries nor to the super-regions used in much of the industry. Hamelink et al. (2000) extend the analysis utilising new groupings based on cluster results in a Markowitz framework. The efficient frontiers of the new groupings dominated conventional classifications in the second half of the time period analysed. The authors argue that this suggests the new groupings reflect a changing economic geography of the UK - a finding echoed in Byrne \& Lee (1998) who use the functional travel-to-work area boundaries of Green \& Owen (1990) to reclassify markets by geography. Jackson (2002) employs a similar procedure for classifying UK retail markets. MacGregor and Schwann (2003) also use the Hillier Parker data to examine common features and common cycles in the data.

These results once again echo the Hoesli et al. results with a strong property type dimension with retail the most clearly defined; the separation of City and West End office markets as distinctive groupings; and an apparent link between central London and Scottish markets perhaps explained by financial services activity. 
That such studies focus almost exclusively on property type and geography results mainly from data availability. In large measure, sector and location are the only variables available for analysis. Further, since the data are either aggregated by market or are hypothetical "beacon" properties, there is no information on within-market variability. However, the conclusions rest very much on homogeneity of returns within each sub-market. One exception to the use of aggregated data is Cullen (1993). Cluster analysis was applied to individual property returns and the higher order clusters examined. Property type does emerge as important. Industrial property appeared to be fairly homogenous (the analysis perhaps precedes the growing importance of large distribution warehouses). Office property has a geographical sub-structure (with City offices distinctive). However, the sub-structure of retail property is less geographical but more sub-divided by lease terms and ownership patterns. This is one of the few suggestions in the formal literature that there may be other important diversification dimensions. The study reported here is in the spirit of Cullen's prior work.

\section{Data and Methods}

The data used in this study are performance figures and descriptive information for individual properties in the Investment Property Databank (IPD) UK database. In particular, a subset of the database comprising properties held over the 10 year period 1995-2004 was examined. In total, 1,728 properties were held over this period and produced returns information in each year. However, because of our interest in exploring the features that characterise returns, we additionally required that a full set of descriptive variables also be available and this reduced the sample to 1,219 properties. The variables in the dataset are listed in Appendix 1. They split broadly into property, tenure, geographical, and return-performance characteristics. For property, we have sector, age and floorspace; tenure-related variables include date to lease expiry and a code to distinguish single and multi-let properties; and for geography, region, town and micro-location. These are augmented by lease and return-linked variables which include capital and rental values, unexpired term, initial and equivalent yields and reversionary potential.

Given the dominance of sector-regional structure models, an initial task is to explore the extent to which such divisions help to explain variation of returns over the analysis period. This task is undertaken using multiple discriminant analysis (MDA). MDA attempts to find an efficient measure of difference between individuals in return space, given a set of prior groupings or classes. Discriminant functions are found which maximise the distance between groups while minimising the distance within groups. Each individual is assigned a discriminant score on each function and, from these discriminant scores, it is possible to determine to which group the building should belong. Thus, the "success rate" - the proportion of buildings correctly classified in their a priori grouping - is a measure of the validity of the sector-region classification. 
Discriminant analyses are run for the standard three sector (office, retail, industrial) classification, the standard three super-region (London, Rest of South East, Other UK) classification, for a nine group (three sector by three region) classification and for a ten group PAS classification ${ }^{4}$. One would expect that, as the number of groups increases, so the number correctly classified will fall. Nonetheless, if the standard models have value in structuring portfolios and in performance measurement, then a high proportion of individual properties should be correctly classified.

Having provided a baseline check on existing classifications, the return structures are explored using a cluster analytic approach. As with Hoesli et al. (1997), we employ a hierarchical agglomeration procedure using the Ward's method (a group centroid, rather than a nearest or furthest neighbour model). Given serial correlation in real estate returns, the returns are first orthogonalised using a standard factor analysis procedure, running a principal component analysis, retaining major factors, and then employing an orthogonal rotation (the conventional varimax process) to improve the interpretability of the final factors.

The fusion stages are examined to see if any natural breaks occur (signalled by a sharp jump in the squared distance measure on fusion). We also examine the ten, nine and three group solutions to match existing classifications. The characteristics of the members of each group are examined - both the standard sector and region variables and other variables including those relating to micro-location and building and leasing attributes. This is intended to identify any other key dimensions that help structure the distribution of returns.

If clear alternative dimensions are found, new a priori groupings will be formed. The new groupings will then be retested using discriminant analysis does the success rate increase with the new groups, suggesting that they form a stronger basis for portfolio strategy and performance attribution? There is some circularity of analysis here: since the clustering has identified the dimensions to produce the new groupings, a higher success rate would be expected. However, the extent of superior classification is a useful indicator. The ideal would be to contrast conventional with new classifications using a hold-out time period. Unfortunately, the Achilles' heel of direct real estate analysis, short time series, precludes such an approach.

\footnotetext{
${ }^{4}$ PAS stands for IPD’s Portfolio Analysis Service rather than for a feature of the classification itself.
} 


\section{Empirical Results}

Multiple discriminant analysis was initially used with annual returns data to examine the "success rate" of classification by sector and by super-region. As Figure 1 shows, $69 \%$ of properties were correctly classified by sector. Confirming prior UK research, retail properties (75\% correct) are most likely to be assigned to their sector, while industrial properties (55\%) are least likely. Again confirming earlier studies, the super-regions are less successful at a classification tool, with only $49 \%$ of buildings correctly assigned to their region. London fares best (with 58\% correctly assigned) but it appears that such broad geographical categorisations are insensitive to return variations. Nonetheless for pragmatic reasons, investors may want to maintain a space variable.

Figure 1: Discriminant Analysis: Three Sectors

\begin{tabular}{|c|c|c|c|c|}
\hline & & \multicolumn{3}{|c|}{ Predicted } \\
\hline \multirow{4}{*}{\begin{tabular}{c} 
咅 \\
\cline { 2 - 5 }
\end{tabular}} & Retail & $\mathbf{4 8 6}$ & 52 & 111 \\
\cline { 2 - 5 } & Office & 36 & $\mathbf{2 1 5}$ & 61 \\
\cline { 2 - 5 } & Industrial & 48 & 67 & $\mathbf{1 4 3}$ \\
\hline
\end{tabular}

Figure 2: Discriminant Analysis: Three Super Regions

\begin{tabular}{|c|c|c|c|c|}
\hline & & \multicolumn{3}{|c|}{ Predicted } \\
\hline \multirow{4}{*}{ 勇 } & & London & $\begin{array}{c}\text { Rest of } \\
\text { South East }\end{array}$ & Rest of UK \\
\cline { 2 - 5 } & London & $\mathbf{1 9 8}$ & 70 & 73 \\
\cline { 2 - 5 } & $\begin{array}{c}\text { Rest of } \\
\text { South East }\end{array}$ & 99 & $\mathbf{1 3 8}$ & 144 \\
\cline { 2 - 5 } & Rest of UK & 81 & 150 & $\mathbf{2 6 6}$ \\
\hline
\end{tabular}

Figure 3: Three by Three Sector Region

\begin{tabular}{|c|c|c|c|c|c|c|c|c|c|c|}
\hline & \multicolumn{9}{|c|}{ Predicted } \\
\hline & & $\begin{array}{l}\text { Ret } \\
\text { Lon }\end{array}$ & $\begin{array}{c}\text { Ret } \\
\text { RoSE }\end{array}$ & $\begin{array}{c}\text { Ret } \\
\text { RoUK }\end{array}$ & $\begin{array}{l}\text { Off } \\
\text { Lon }\end{array}$ & $\begin{array}{c}\text { Off } \\
\text { RoSE }\end{array}$ & $\begin{array}{c}\text { Off } \\
\text { RoUK }\end{array}$ & $\begin{array}{l}\text { Ind } \\
\text { Lon }\end{array}$ & $\begin{array}{c}\text { Ind } \\
\text { RoSE }\end{array}$ & $\begin{array}{l}\text { Ind } \\
\text { UK }\end{array}$ \\
\hline \multirow{9}{*}{ 兑 } & Retail London & 63 & 28 & 21 & 13 & 8 & 8 & 14 & 3 & 7 \\
\hline & Retail RoSE & 17 & 66 & 32 & 2 & 6 & 14 & 10 & 1 & 14 \\
\hline & Retail RoUK & 48 & 100 & 81 & 1 & 21 & 18 & 20 & 6 & 27 \\
\hline & Office London & 10 & 2 & 3 & 69 & 29 & 6 & 13 & 8 & 1 \\
\hline & Office RoSE & 3 & 3 & 2 & 21 & 48 & 18 & 2 & 1 & 10 \\
\hline & Office RoUK & 0 & 5 & 1 & 3 & 10 & 34 & 3 & 3 & 4 \\
\hline & $\begin{array}{l}\text { Industrial } \\
\text { London }\end{array}$ & 5 & 1 & 1 & 3 & 0 & 3 & 17 & 3 & 2 \\
\hline & Industrial RoSE & 9 & 2 & 4 & 10 & 21 & 18 & 19 & 22 & 6 \\
\hline & Industrial RoUK & 11 & 4 & 7 & 4 & 9 & 21 & 15 & 17 & 24 \\
\hline
\end{tabular}


The next test examined a three-by-three sector and region classification. As might be expected, the proportion of buildings correctly classified falls sharply (it is a more exacting test). Only 35\% of buildings are assigned to their "prior" category ${ }^{5}$. Retail and office buildings are classified to their appropriate sector $70 \%$ of the time, but the region categories appear to be unhelpful, with only London having more than $50 \%$ of buildings correctly assigned to the region. With only just over a third of properties correctly classified, the standard sector-region split is called into question.

The ten category PAS segments, used for attribution analysis and performance benchmarking perform little better. Overall, once again, around 35\% of buildings are assigned to their prior PAS categories. Only three segments have a greater than $50 \%$ success rate: Retail Warehouses (64\%); Rest of UK Offices (62\%); and City of London Offices (62\%) - in the last case there are only 26 observations. Office and retail properties are correctly sorted by sector with $80 \%$ of offices and $79 \%$ of retail units correctly assigned. However, standard shop units are less successfully distinguished from other retail categories, with only $51 \%$ placed in the right sub-sector.

On the basis of this analysis, it would seem that the standard sector-region groupings have some validity but do not characterise the variability of returns over time. The next step, then, involved clustering the individual buildings and examining the attributes of the buildings in each cluster. Since the hierarchical agglomeration clustering procedure uses a Euclidean squared distance measure, the returns were first orthogonalised using a factor analytic procedure. A principal components analysis was run and the eigenvalues were examined. The first five components explained $63 \%$ of the variation in returns and hence were retained (eigenvalues retained ranged from 1.89 to 0.95 - the fifth component was retained, following standard practice, as a "clean up" factor. A varimax rotation procedure allowed clearer interpretation of the factors, which are linked to pairs of years. This result was surprising but turned out to be consistent with the pattern of correlation across years, implying a strong common factor in returns in any one year and a degree of serial correlation across years. Component scores for the five rotated factors were retained and used in the clustering procedure.

The cluster stages identified by the hierarchical process do not exhibit any sharp discontinuities in fusion distance that would point to a particular number of groups being optimal. Figure 4 shows the final fusion stages from a nine group solution and Figure 5 the cumulative squared distances for the last fifty fusions. Given the lack of an obvious "slope change" in the squared distance measure on fusion, we examine the characteristics of the three group and the nine group solutions to provide direct compatibility with the conventional three group (sector or super-region) and nine group (sector-region) models used in conventional analysis. Similar results are available from the authors for the ten group solution but are not discussed here.

\footnotetext{
${ }^{5}$ All these tables generate strongly significant chi-squared statistics, but this is largely a function of sample size.
} 
Figure 4 Dendrogram, Hierarchical Cluster, Final Eight Stages

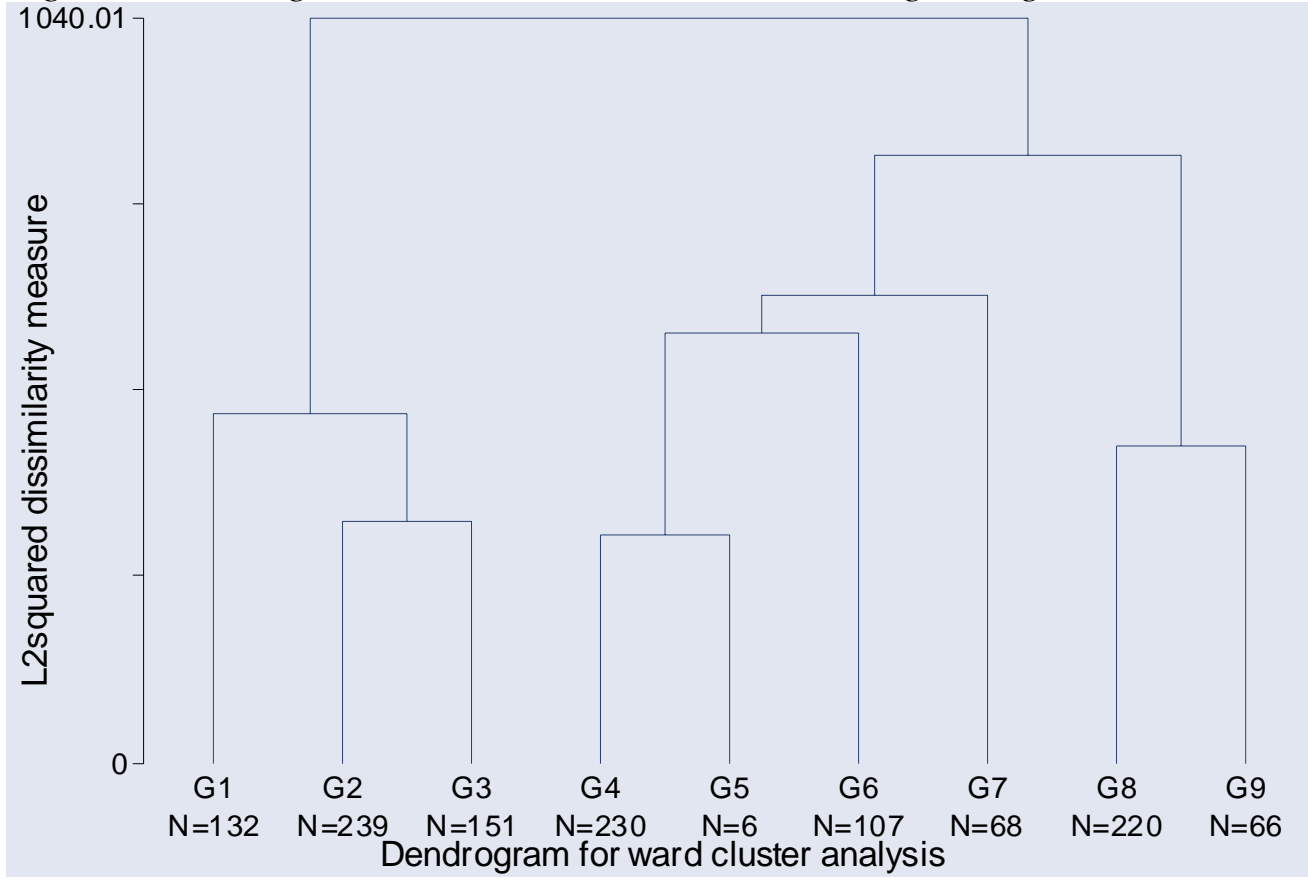

Figure 5 Fusion Distances, Last 50 Stages

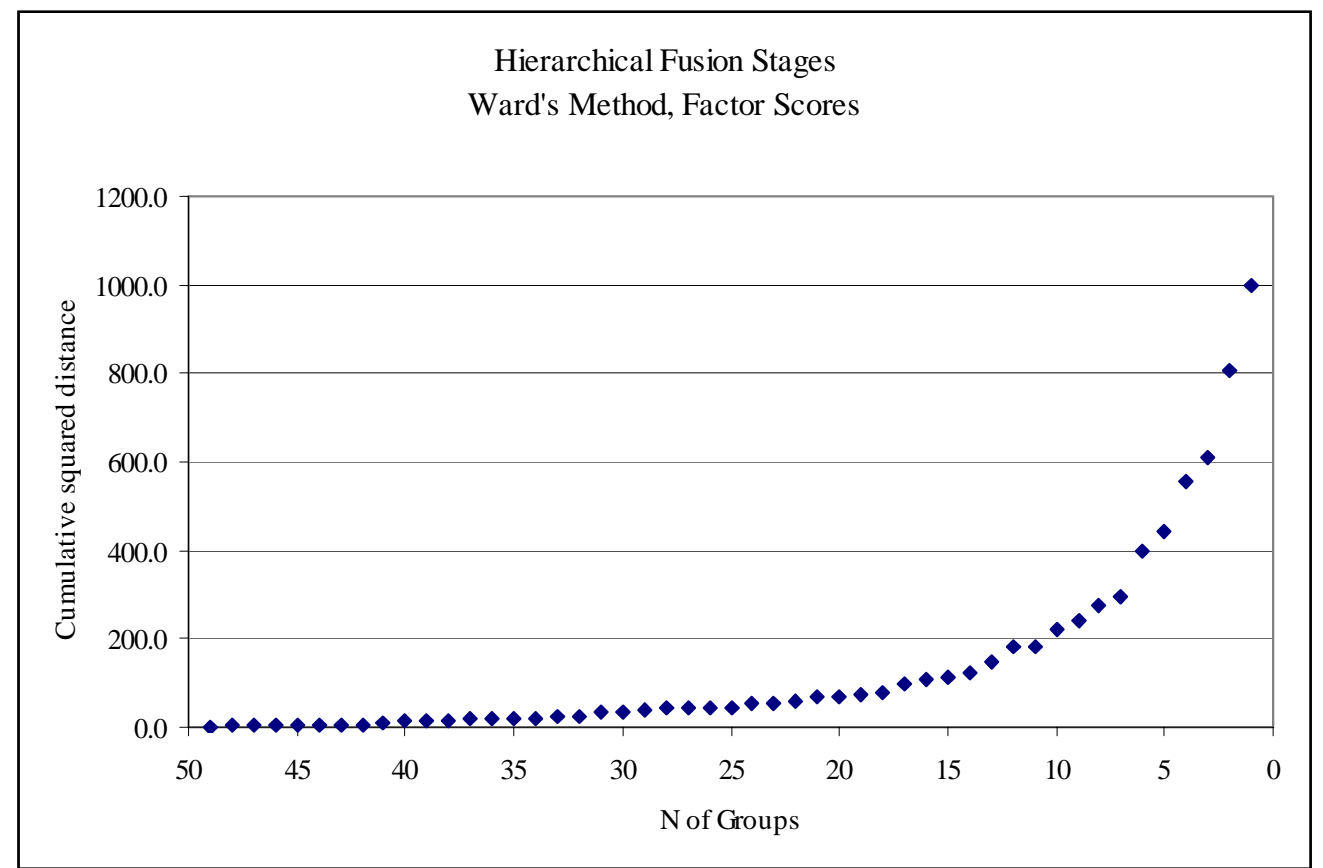

Figure 6 provides summary information characterising the membership of clusters for the nine group solution. Appendix 2 repeats the analysis for the three group solution. 
Figure 6: Cluster Characteristics, Nine Group Solution.

Panel A: Sector and Region Concentration

\begin{tabular}{|c|c|c|c|c|}
\hline Group & Count & $\begin{array}{c}\text { Max \% in Any } \\
\text { One Sector }\end{array}$ & $\begin{array}{l}\text { Max \% in Any } \\
\text { One Region }\end{array}$ & $\begin{array}{c}\text { Ratio Single } \\
\text { to Multi let }\end{array}$ \\
\hline 1 & 132 & 97\% Retail & 55\% Rest UK & 3.55 \\
\hline 2 & 239 & 48\% Office & 39\% RoSE & 1.49 \\
\hline 3 & 151 & 64\% Retail & $62 \%$ Rest UK & 1.48 \\
\hline 4 & 230 & 54\% Retail & 37\% Rest UK & 1.13 \\
\hline 5 & 6 & $50 \%$ Office & 83\% London & 1.00 \\
\hline 6 & 107 & 76\% Retail & $42 \%$ Rest UK & 1.61 \\
\hline 7 & 68 & 37\% Office & 40\% London & 0.66 \\
\hline 8 & 220 & 45\% Retail & $40 \%$ Rest UK & 0.73 \\
\hline 9 & 66 & 61\% Retail & $48 \%$ London & 1.36 \\
\hline & & & & \\
\hline Dataset & 1,219 & $53 \%$ Retail & $41 \%$ Rest UK & 1.28 \\
\hline
\end{tabular}

Panel B: Building and Tenure Characteristics

\begin{tabular}{|c|c|c|c|c|}
\hline Group & & Floorspace & Age & $\begin{array}{l}\text { Term to } \\
\text { Expiry }\end{array}$ \\
\hline \multirow[t]{2}{*}{1} & Average & 1007 & 81 & 10.9 \\
\hline & St Deviation & 1386 & 59 & 5.3 \\
\hline \multirow[t]{2}{*}{2} & Average & 4411 & 47 & 11.9 \\
\hline & St Deviation & 6467 & 54 & 4.9 \\
\hline \multirow[t]{2}{*}{3} & Average & 3259 & 56 & 12.2 \\
\hline & St Deviation & 4419 & 54 & 5.4 \\
\hline \multirow[t]{2}{*}{4} & Average & 4139 & 53 & 11.9 \\
\hline & St Deviation & 9249 & 49 & 6.0 \\
\hline \multirow[t]{2}{*}{5} & Average & 2416 & 93 & 6.1 \\
\hline & St Deviation & 2524 & 67 & 3.9 \\
\hline \multirow[t]{2}{*}{6} & Average & 3305 & 63 & 11.5 \\
\hline & St Deviation & 6016 & 50 & 6.3 \\
\hline \multirow[t]{2}{*}{7} & Average & 4710 & 51 & 9.2 \\
\hline & St Deviation & 5602 & 40 & 5.3 \\
\hline \multirow[t]{2}{*}{8} & Average & 6880 & 51 & 11.7 \\
\hline & St Deviation & 11288 & 56 & 5.9 \\
\hline \multirow[t]{2}{*}{9} & Average & 2369 & 78 & 10.7 \\
\hline & St Deviation & 3167 & 60 & 6.2 \\
\hline \multirow[t]{2}{*}{ Dataset } & Average & 4093 & 57 & 11.5 \\
\hline & St Deviation & 7616 & 54 & 5.7 \\
\hline
\end{tabular}


Panel C: Return Characteristics

\begin{tabular}{|c|c|c|c|c|c|c|c|c|}
\hline Group & & $\begin{array}{l}\text { Capital } \\
\text { Value } \\
\text { End-94 }\end{array}$ & $\begin{array}{l}\text { Initial } \\
\text { Yield } \\
\text { End-94 }\end{array}$ & $\begin{array}{c}\text { Equivalent } \\
\text { Yield at } \\
\text { End-94 }\end{array}$ & $\begin{array}{c}\text { Annualised } \\
\text { Total } \\
\text { Return }\end{array}$ & $\begin{array}{l}\text { Annualised } \\
\text { Capital } \\
\text { Growth }\end{array}$ & $\begin{array}{c}\text { Annualised } \\
\text { Rental } \\
\text { Growth }\end{array}$ & $\begin{array}{c}\text { Annualised } \\
\text { Yield } \\
\text { Impact }\end{array}$ \\
\hline \multirow{2}{*}{1} & Average & 3954000 & 5.4 & 5.9 & 8.9 & 2.7 & 3.4 & -0.2 \\
\hline & St Deviation & 5222000 & 1.5 & 1.2 & 2.1 & 2.1 & 1.9 & 1.4 \\
\hline \multirow{2}{*}{2} & Average & 6723000 & 7.2 & 7.9 & 9.7 & 1.9 & 2.7 & 0.5 \\
\hline & St Deviation & 9214000 & 2.3 & 1.8 & 2.0 & 2.4 & 2.1 & 1.7 \\
\hline \multirow{2}{*}{3} & Average & 3448000 & 6.9 & 7.7 & 10.4 & 2.1 & 2.1 & 0.7 \\
\hline & St Deviation & 3289000 & 2.3 & 2.0 & 2.9 & 2.4 & 2.0 & 1.9 \\
\hline \multirow{2}{*}{4} & Average & 4241000 & 7.5 & 8.4 & 12.9 & 4.8 & 4.0 & 1.9 \\
\hline & St Deviation & 4851000 & 2.6 & 2.0 & 2.8 & 2.6 & 2.3 & 1.7 \\
\hline \multirow{2}{*}{5} & Average & 1896000 & 5.3 & 9.8 & 14.0 & 7.6 & 5.2 & 2.3 \\
\hline & St Deviation & 2504000 & 5.1 & 2.8 & 3.9 & 3.7 & 2.7 & 2.0 \\
\hline \multirow{2}{*}{6} & Average & 3117000 & 7.9 & 8.6 & 15.1 & 6.4 & 4.7 & 2.5 \\
\hline & St Deviation & 3355000 & 2.2 & 2.1 & 2.8 & 2.8 & 2.4 & 1.7 \\
\hline \multirow{2}{*}{7} & Average & 3137000 & 9.3 & 9.9 & 15.3 & 5.6 & 4.7 & 2.3 \\
\hline & St Deviation & 2525000 & 3.5 & 2.5 & 3.9 & 4.3 & 3.6 & 2.4 \\
\hline \multirow{2}{*}{8} & Average & 6330000 & 8.1 & 9.2 & 14.1 & 5.7 & 4.5 & 2.4 \\
\hline & St Deviation & 13780000 & 3.2 & 2.3 & 2.8 & 3.0 & 2.7 & 1.8 \\
\hline \multirow{2}{*}{9} & Average & 3381000 & 7.1 & 8.7 & 14.4 & 7.2 & 5.5 & 2.5 \\
\hline & St Deviation & 3508000 & 3.7 & 2.9 & 3.2 & 3.0 & 2.3 & 2.3 \\
\hline \multirow{3}{*}{ Dataset } & & & & & & & & \\
\hline & Average & 4757000 & 7.4 & 8.2 & 12.2 & 4.2 & 3.7 & 1.5 \\
\hline & St Deviation & 7967000 & 2.8 & 2.3 & 3.5 & 3.3 & 2.6 & 2.0 \\
\hline
\end{tabular}

Perhaps the most striking feature of the groups is their heterogeneity. For the standard classification variables, Panel A shows that even sector does not emerge clearly, save Group 1, which is a cluster of standard shops. Group 6 is also dominated by retail. However the individual buildings are not sorted by region and there is little separation of office and industrial property. There are no obvious spatial patterns when individual disaggregated regions or property sub-sectors are considered. Given this lack of homogeneity, the three group solution neither identifies sectors nor regions. The standard shops in Group 1 are, as expected, more likely to be single let than the sample as whole.

Panel B analyses some building characteristics. The shops in Group 1 tend to be smaller than sample properties in general, but even here there is considerable variation within the group, as shown by the standard deviation. To an extent, size is also acting as a proxy for property sub-sector. Few of the cluster means are statistically different from the overall sample mean. Similarly, while there are variations in mean age and mean term to expiry, the within-group variation makes it near impossible to characterise the clusters.

Panel C characterises the groups in terms of values, yields and returns. The differences that are observed in the return and growth series are not particularly helpful, since we are clustering on delivered returns. Equivalent and initial yields are ex ante measures of performance and there are some large differences in mean group yields compared to the average yields in the sample, although to some extent this may be a proxy for the typically lower 
yields of retail units. There do appear to be yield differences between groups that are not dominated by retail, however which may imply some separation of properties delivering growth from properties delivering income - which would mirror equity market characterisations of stocks. An alternative explanation would be the traditional property distinction between prime and secondary.

In summary, the results from the clustering process neither validate standard classifications, nor point to clear alternative dimensions for structuring a real estate portfolio. Geography appears to have little explanatory power, at least at any aggregated level. If there is a sector impact, it is almost entirely attributable to retail property - and, within retail, to standard shops. This, at least, confirms prior research. Of other explanatory variables, tenancy structure, size of unit and capitalisation rate appear to differ across groups but, even here, there is considerable within group variation. Looking at the clusters that have been fused into the nine-group solution does not create clarity - the characteristic heterogeneity appears to be pervasive.

As a first step to exploring other factors that may help differentiate properties, we examined the impact of yield and tenancy structure. For yields, we used the equivalent yield variable and, initially split the sample into three equal sized groups. The boundaries (recall that these are 1994 yields) are $7.13 \%$ and $8.96 \%$. Figure 7 shows the assignments from a discriminant analysis based on yields alone. $61 \%$ of buildings are correctly assigned - only a slightly worse performance than for the three way sector split. Had the low-medium-high boundaries been optimised, it seems likely that a higher "success rate could have been achieved. $74 \%$ of low yielding properties and $62 \%$ of high yielding properties were correctly assigned.

Figure 7: Discriminant Analysis: Equivalent Yield Bands

\begin{tabular}{|c|c|c|c|c|}
\hline & & \multicolumn{3}{|c|}{ Predicted } \\
\hline \multirow{3}{*}{\begin{tabular}{c} 
胥 \\
\cline { 2 - 5 }
\end{tabular}} & Low & $\mathbf{3 0 1}$ & 76 & 30 \\
\cline { 2 - 5 } & Medium & 100 & $\mathbf{1 9 5}$ & 111 \\
\cline { 2 - 5 } & High & 32 & 123 & $\mathbf{2 5 1}$ \\
\cline { 2 - 5 } & & 32 & Medium & High \\
\hline
\end{tabular}

To match the sector-region nine group classification, the analysis was extended to a three by three matrix of sector and yield. Since there is some relationship between sector and yield (with retail more likely to be low yielding and industrial more likely to be high yielding), the properties within each sector were divided into three equal groups by yield. The boundaries for retail, office and industrial were, respectively, $6.1 \%$ and $7.8 \% ; 7.9 \%$ and $8.3 \%$; and $8.9 \%$ and $10.5 \%$. Figure 8 shows the allocations. $43 \%$ of buildings are correctly classified, compared to the 35\% correctly classified in the conventional sector region model. Hence size of yield seems to have greater information content than geography. As with the simple yield analysis, low and high yielding buildings are more likely to be correctly assigned than those in the middle yield group, suggesting that greater refinement is feasible. 
Figure 8: Discriminant Analysis: Sector and Equivalent Yield

\begin{tabular}{|c|c|c|c|c|c|c|c|c|c|c|}
\hline & \multicolumn{9}{|c|}{ Predicted } \\
\hline & & $\begin{array}{l}\text { Ret } \\
\text { Low }\end{array}$ & $\begin{array}{l}\text { Ret } \\
\text { Mid }\end{array}$ & $\begin{array}{c}\text { Ret } \\
\text { High }\end{array}$ & $\begin{array}{c}\text { Off } \\
\text { Low }\end{array}$ & $\begin{array}{c}\text { Off } \\
\text { Med }\end{array}$ & $\begin{array}{c}\text { Off } \\
\text { High }\end{array}$ & $\begin{array}{l}\text { Ind } \\
\text { Low }\end{array}$ & $\begin{array}{l}\text { Ind } \\
\text { Med }\end{array}$ & $\begin{array}{c}\text { Ind } \\
\text { High }\end{array}$ \\
\hline \multirow{9}{*}{$\begin{array}{l}\stackrel{D}{D} \\
\stackrel{D}{D} \\
\text { D }\end{array}$} & Retail Low & 145 & 31 & 5 & 8 & 4 & 0 & 19 & 4 & 1 \\
\hline & Retail Med & 51 & 64 & 46 & 11 & 6 & 2 & 17 & 7 & 12 \\
\hline & Retail High & 8 & 45 & 102 & 3 & 1 & 4 & 15 & 15 & 23 \\
\hline & Office Low & 1 & 3 & 4 & 58 & 12 & 7 & 14 & 4 & 1 \\
\hline & Office Med & 0 & 6 & 3 & 27 & 24 & 18 & 18 & 2 & 6 \\
\hline & Office High & 2 & 3 & 7 & 10 & 16 & 32 & 7 & 8 & 19 \\
\hline & Industrial Low & 5 & 7 & 3 & 18 & 5 & 1 & 33 & 8 & 6 \\
\hline & Industrial Med & 1 & 9 & 7 & 3 & 12 & 7 & 10 & 27 & 10 \\
\hline & Industrial High & 1 & 9 & 9 & 1 & 5 & 15 & 2 & 10 & 34 \\
\hline
\end{tabular}

Finally, to test the impact of tenancy, we examined a six group split with sector set against either single letting or a multiple letting. 45\% of buildings are correctly classified, a higher proportion than either the sector-region or PAS Segments results reported above (but with fewer groups, making correct classification less onerous). The proportions of properties correctly assigned to their sector increases over the geography-sector models and some $62 \%$ of properties are correctly assigned by tenancy status. Again, this is a relatively strong result given possible inconsistencies of coding between fund managers (for example is a row of shops one property with multiple tenants or a number of separate properties?).

Figure 9: Discriminant Analysis: Sector and Tenancy Status

\begin{tabular}{|c|l|c|c|c|c|c|c|}
\hline \multicolumn{2}{|c|}{} & $\begin{array}{c}\text { Ret } \\
\text { Sing }\end{array}$ & $\begin{array}{c}\text { Ret } \\
\text { ML }\end{array}$ & $\begin{array}{c}\text { Off } \\
\text { Sing }\end{array}$ & $\begin{array}{c}\text { Off } \\
\text { ML }\end{array}$ & $\begin{array}{c}\text { Ind } \\
\text { Sing }\end{array}$ & $\begin{array}{c}\text { Ind } \\
\text { ML }\end{array}$ \\
\hline \multirow{4}{*}{$\underset{\nexists}{\stackrel{2}{\rightleftarrows}}$} & Retail Single & $\mathbf{2 2 0}$ & 101 & 33 & 7 & 29 & 21 \\
\cline { 2 - 8 } & Retail Multi & 71 & $\mathbf{9 3}$ & 20 & 10 & 19 & 25 \\
\cline { 2 - 8 } & Office Single & 8 & 13 & $\mathbf{7 2}$ & 39 & 9 & 17 \\
\cline { 2 - 8 } & Office Multi & 2 & 6 & 31 & $\mathbf{7 9}$ & 18 & 18 \\
\cline { 2 - 8 } & Industrial Single & 11 & 19 & 29 & 8 & $\mathbf{2 7}$ & 22 \\
\cline { 2 - 8 } & Industrial Multi & 4 & 15 & 16 & 16 & 32 & $\mathbf{5 9}$ \\
\hline
\end{tabular}

In summary, disaggregated sector-region classifications have limited information content when individual property returns are considered. As in prior research, sector outperforms region, but this result comes largely from the distinctiveness of retail property. Much of the retail effect can be explained in terms of capitalisation rate (yield) and, possibly, unit size. Cluster analysis fails to identify clear groups or alternative classification dimensions, with group membership appearing to be heterogeneous with respect to a range of building, location and tenancy characteristics - although both equivalent yield and single versus multi-let status appear to have some impact on return behaviour. 


\section{Conclusions}

The practice of basing portfolio structure and performance measurement on a sector-region breakdown of property as an asset class relies on these dimensions having explanatory power in delineating return distributions. Prior UK research has tended to confirm the importance of sector but casts doubt on the validity of conventional geographical boundaries. However, investors directly owning portfolios of properties are not investing in sectoral indices, they hold buildings - and often not many buildings (IPD-tracked portfolios had an average size of 45 at the end of 2004). As a result, for sector-region dimensions to be valuable, they must hold at the individual level.

Analysis based on a sample of some 1,200 properties suggests that sector and geography are, at best, weak explanatory factors for the distribution of returns. The conventional three sector division does identify a retail dimension, but aggregated regional boundaries add little to understanding. Barely a third of properties are correctly classified by the discriminant analysis into their PAS categories. This seems to result from heterogeneity at individual property level: finer, disaggregated breakdowns are no more successful in classifying properties than the three sector, three region models conventionally employed.

Investigating the characteristics of groupings produced by cluster analysis adds little clarity. There are no obvious factors relating to the buildings themselves that offer superior explanations. There appears to be some relationship between behaviour and capitalisation rate (that is, equivalent yield), single versus multi-let properties and size of building, but within-group variation is very high. The conclusions seem to be that the treatment of real estate from outside the sector - as a single asset class, not one differentiated by sub-segments - may be valid. Within property, there may be a distinction between growth and income properties - with the sector, property type and location variables proxying for that. A further conclusion is that, in order to track a sub-sector index, for example south east offices, an investor would need to hold a very large portfolio to remove the impact of heterogeneity. In a sense, the "south east retail" performance is simply a statistical artefact. This has interesting implications as property derivatives markets based on swap returns emerge and as specialist private equity vehicles increase in importance in investment portfolios.

Pragmatically, those organisations managing directly held property funds need to partition property for operational reasons. Geography will continue to be important insofar as real estate requires active management and visits - a geographical patch minimises distance and local knowledge is important in stock selection. Institutional traditions and market structures may continue to embed the idea that surveyors or agents are "retail specialists" or "office specialists" - although the research presented here casts doubt on the validity of such a distinction. Is there any reason why a surveyor could not be an expert in "income properties" or "growth properties"? 


\section{References}

Brown, G. (1988) Reducing the Dispersion of Returns in UK Real Estate Portfolios, Journal of Valuation, 6, 127-147.

Byrne, P. \& Lee, S. (1998) Diversification by Sector, Region or Function? A Mean Absolute Deviation Optimisation, Journal of Property Valuation \& Investment, 16, 38-56.

Byrne, P.\& Lee, S. (2000) Risk Reduction in the UK Property Market, Journal of Property Research, 17, 23-46.

Byrne, P.\& Lee, S. (2001) Risk Reduction and Portfolio Size, Managerial and Decision Economics, 22, 369-379.

Byrne, P.\& Lee, S. (2003) An Exploration of the Relationship Between Size, Diversification and Risk in UK Real Estate Portfolios, Journal of Property Research, 20, 191-206.

Cullen, I. (1993) Cluster Analysis and Property Risk in The Cutting Edge: Proceedings of the RICS Property Research Conference, 21-36, London: Royal Institution of Chartered Surveyors.

Green, A. \& Owen, D. (1990) The Development of a Classification of Travel to Work Areas, Progress in Planning, 34, 9-91.

Hamelink, F., Hoesli, M., Lizieri, C. \& MacGregor, B. (2000) Homogenous Commercial Property Market Groupings and Portfolio Construction in the United Kingdom, Environment and Planning A, 32, 323-344

Hoesli, M., Lizieri, C. \& MacGregor, B. (1997) The Spatial Dimensions of the Investment Performance of UK Commercial Property, Urban Studies, 34, 14751494.

Jackson, C. (2002) Classifying Local Retail Property Markets on the Basis of Retail Rental Growth Rates, Urban Studies, 38, 1445-1471.

Lee, S. (2003) Correlation Shifts and Real Estate Portfolio Management, The Journal of Real Estate Portfolio Management, 9, 45-58.

MacGregor, B \& Schwann, G. (2003) Common Features in UK Commercial Real Estate Returns, Journal of Property Research, 20, 23-48.

Morrell, G. (1993) Value-Weighting and the Variability of Real Estate Returns, Journal of Property Research, 10, 167-183.

Nelson, T. \& Nelson, S. (2003) Regional Models for Portfolio Diversification, Journal of Real Estate Portfolio Management, 9, 71-88.

Schuck \& Brown, G. (1997) Value Weighting and Real Estate Risk, Journal of Property Research, 14, 169-188.

Viezer, T. (2000) Evaluating 'Within Real Estate' Diversification, Journal of Real Estate Portfolio Management, 6, 75-98.

Worzala, E., Gilliland, D. \& Gordon, J. (2002) Research Needs of the Plan Sponsor, Journal of Real Estate Portfolio Management, 8, 65-77. 
Appendix 1: Variables in the Dataset

\begin{tabular}{|c|c|}
\hline Variable & Description \\
\hline Total returns & For each year 1995-2004. \\
\hline Capital growth & For each year 1995-2004. \\
\hline Rental value growth & $\begin{array}{l}\text { Change in open market rental value (OMRV) over } \\
\text { period. For each year 1995-2004. }\end{array}$ \\
\hline Yield impact & $\begin{array}{l}\text { The influence on capital growth of yield changes over } \\
\text { period. For each year 1995-2004. }\end{array}$ \\
\hline Capital values & For each year $1995-2004$ \\
\hline Initial yield at start & Rent passing as a \% of value as at December 1994. \\
\hline Equivalent yield at start & $\begin{array}{l}\text { The discount rate that equates projected future income } \\
\text { flows to the gross capital value. As at December } 1994 \text {. }\end{array}$ \\
\hline Reversionary potential & $\begin{array}{l}\text { A ratio expressing the potential rental uplift available } \\
\text { in a property upon review or letting. As at December } \\
1994 \text {. }\end{array}$ \\
\hline Property type & $\begin{array}{l}\text { Describes type of building and is used to construct } \\
\text { sector dimension in segmentations. }\end{array}$ \\
\hline Region & $\begin{array}{l}\text { Denotes region where property is located and is used } \\
\text { to construct regional dimension in segmentations. }\end{array}$ \\
\hline Town & Denotes town where property is located. \\
\hline Tenure & $\begin{array}{l}\text { Whether the property is held freehold or on long } \\
\text { leasehold by the investor. }\end{array}$ \\
\hline Age & $\begin{array}{l}\text { Calculated from the date of construction / date of last } \\
\text { major refurbishment. }\end{array}$ \\
\hline Retail location & $\begin{array}{l}\text { Micro-location code indicating e.g. town centre, } \\
\text { suburb. }\end{array}$ \\
\hline Office location & Micro-location code indicating e.g. central, suburb. \\
\hline Industrial location & $\begin{array}{l}\text { Micro-location code indicating e.g. near motorway, } \\
\text { airport. }\end{array}$ \\
\hline Floor space & In square metres. \\
\hline Capital expenditure rate & $\begin{array}{l}\text { The amount of capital expenditure over the period } \\
\text { expressed as a proportion of capital values. }\end{array}$ \\
\hline Single/multi let & $\begin{array}{l}\text { A } 0 / 1 \text { variable indicating whether the property has one } \\
\text { or more than one tenant. }\end{array}$ \\
\hline Un-expired term & $\begin{array}{l}\text { A weighted average across each property's leases of } \\
\text { the number of years left until expiry. Calculated with } \\
\text { and without the impact of break clauses. This can only } \\
\text { be calculated as at December } 1998 \text { and onwards. }\end{array}$ \\
\hline Void amount & $\begin{array}{l}\text { The proportion of ERV in the property that was void. } \\
\text { This can only be calculated as at December } 1998 \text { and } \\
\text { onwards. }\end{array}$ \\
\hline
\end{tabular}




\section{Appendix Two: Characteristics of the Three Group Cluster Solution}

Panel A: Sector and Region Concentration

\begin{tabular}{|c|c|c|c|c|}
\hline Group & Count & $\begin{array}{c}\text { Max \% in Any } \\
\text { One Sector }\end{array}$ & $\begin{array}{c}\text { Max \% in Any } \\
\text { One Region }\end{array}$ & $\begin{array}{c}\text { Ratio Single to } \\
\text { Multi let }\end{array}$ \\
\hline 1 & 522 & $54 \%$ Retail & $47 \%$ Rest UK & 1.81 \\
\hline 2 & 411 & $55 \%$ Retail & $36 \%$ Rest UK & 1.13 \\
\hline 3 & 286 & $49 \%$ Retail & $38 \%$ London & 0.85 \\
\hline & & & & $\mathbf{1 1 \%}$ Rest \\
\hline Dataset & $\mathbf{1 , 2 1 9}$ & $\mathbf{5 3 \% \text { Retail }}$ & $\mathbf{4 1 \%}$ & \\
\hline
\end{tabular}

Panel B: Building and Tenure Characteristics

\begin{tabular}{|c|l|c|c|c|}
\hline Group & & Floorspace & Age & $\begin{array}{c}\text { Term to } \\
\text { Expiry }\end{array}$ \\
\hline & & & & $\mathbf{1 1 . 7}$ \\
\hline 1 & Average & $\mathbf{3 2 1 7}$ & $\mathbf{5 8}$ & 5.2 \\
\hline & St Deviation & 5206 & 57 & $\mathbf{1 1 . 2}$ \\
\hline 2 & Average & $\mathbf{3 9 9 1}$ & $\mathbf{5 6}$ & 6.1 \\
\hline & St Deviation & 7912 & 48 & $\mathbf{1 1 . 5}$ \\
\hline 3 & Average & $\mathbf{5 8 3 9}$ & $\mathbf{5 7}$ & 6.0 \\
\hline & St Deviation & 10189 & 58 & $\mathbf{1 1 . 5}$ \\
\hline & & & & 5.7 \\
\hline
\end{tabular}

Panel C: Return Characteristics

\begin{tabular}{|c|c|c|c|c|c|c|c|c|}
\hline Group & & $\begin{array}{c}\text { Capital } \\
\text { Value } \\
\text { End-94 }\end{array}$ & $\begin{array}{c}\text { Initial } \\
\text { Yield } \\
\text { End-94 }\end{array}$ & $\begin{array}{c}\text { Equivalent } \\
\text { Yield at } \\
\text { End-94 }\end{array}$ & $\begin{array}{c}\text { Annualised } \\
\text { Total } \\
\text { Return }\end{array}$ & $\begin{array}{c}\text { Annualised } \\
\text { Capital } \\
\text { Growth }\end{array}$ & $\begin{array}{c}\text { Annualised } \\
\text { Rental } \\
\text { Growth }\end{array}$ & $\begin{array}{c}\text { Annualised } \\
\text { Yield } \\
\text { Impact }\end{array}$ \\
\hline \multirow{2}{*}{1} & Average & 5076000 & 6.7 & 7.3 & 9.7 & 2.2 & 2.7 & 0.4 \\
\hline & St Deviation & 7147000 & 2.2 & 1.9 & 2.4 & 2.4 & 2.1 & 1.7 \\
\hline \multirow{2}{*}{2} & Average & 3731000 & 7.9 & 8.7 & 13.9 & 5.4 & 4.3 & 2.1 \\
\hline & St Deviation & 4186000 & 2.8 & 2.2 & 3.2 & 3.1 & 2.6 & 1.9 \\
\hline \multirow{2}{*}{3} & Average & 5650000 & 7.9 & 9.1 & 14.2 & 6.1 & 4.7 & 2.4 \\
\hline & St Deviation & 12250000 & 3.3 & 2.5 & 2.9 & 3.1 & 2.6 & 1.9 \\
\hline \multirow{2}{*}{ Dataset } & Average & 4757000 & 7.4 & 8.2 & 12.2 & 4.2 & 3.7 & 1.5 \\
\hline & St Deviation & 7967000 & 2.8 & 2.3 & 3.5 & 3.3 & 2.6 & 2.0 \\
\hline
\end{tabular}

